O Open Access Full Text Article

\title{
Discovery of a Novel Benzenesulfonamide
}

\section{Analogue That Inhibits Proliferation and Metastasis Against Ovarian Cancer OVCAR-8 Cells}

This article was published in the following Dove Press journal:

Drug Design, Development and Therapy

\section{Yanyan Jia \\ Meijuan Li \\ Yuan Cao \\ Wenlong Feng \\ Xueru Li \\ Wenhua Xue \\ Huirong Shi}

Department of Gynecology and Obstetrics, The First Affiliated Hospital of Zhengzhou University, Zhengzhou 450052, People's Republic of China
Correspondence: Yanyan Jia

Department of Gynecology and

Obstetrics, The First Affiliated Hospital of

Zhengzhou University, Jianshe East Road,

Zhengzhou 450052, People's Republic of

China

Email jiayy2019@I63.com
Background: Ovarian cancer has been a salient public health concern in the world. It is necessary to develop novel antitumor drugs to treat ovarian cancer.

Purpose: This study investigated the synthesis, antiproliferation ability, antitumor mechanisms in vitro and in vivo of a novel benzenesulfonamide derivative.

Methods: The novel benzenesulfonamide-1,2,3-triazole hybrid 7c was synthesized from 4-fluorobenzenesulfonyl chloride, prop-2-yn-1-amine and 1-(azidomethyl)-3-phenoxybenzene. The structure of this benzenesulfonamide-1,2,3-triazole hybrid 7c was confirmed by ${ }^{13} \mathrm{C} \mathrm{NMR}$, and ${ }^{1} \mathrm{H}$ NMR. Compound $\mathbf{7 c}$ was evaluated for its antitumor effects in vitro and in vivo against ovarian cancer OVCAR-8 cells.

Results: We discovered that the benzenesulfonamide hybrid $7 \mathbf{c}$ potently inhibited cell proliferation against ovarian cancer. Especially, it inhibited cell proliferation with an $\mathrm{IC}_{50}$ value of $0.54 \mu \mathrm{M}$ against OVCAR-8 cells. It could inhibit migration and invasion against OVCAR-8 cells in a concentration-dependent and time-dependent manner. In addition, compound 7c affected the Wnt/ $\beta$-catenin/GSK3 $\beta$ pathway against ovarian cancer OVCAR- 8 cells. In vivo study suggested that compound 7c inhibited tumor growth remarkably without obvious toxicity.

Conclusion: In conclusion, benzenesulfonamide hybrid $\mathbf{7 c}$ could be a lead compound for further antitumor drug discovery to treat ovarian cancer.

Keywords: benzenesulfonamide, proliferation, migration, invasion, in vivo

\section{Introduction}

Ovarian cancer as a salient public health concern remains the deadliest form of gynaecological malignancy. ${ }^{1,2}$ According to the world health organization, an estimated total of 226,000 cases of ovarian cancer will be diagnosed and 140,200 patients will succumb to this disease every year in the world, representing the seventh most common form of cancer in women. ${ }^{3,4}$ Therefore, discovery of potent drugs against ovarian cancer is very necessary.

Benzenesulfonamide has become a biologically important object since its presence in the therapeutic application as the antitumor agent. ${ }^{5,6}$ Benzenesulfonamide derivative 1 (Figure 1) was known as a potent receptor tyrosine kinase inhibitor to treat renal cell carcinoma. ${ }^{7}$ Benzenesulfonamide derivative $\mathbf{2}$ was found to have a significant effect on the inhibition of antiapoptotic proteins $\mathrm{Bcl} 2$ and $\mathrm{BclxL}$ against HT-29 cells and SW620 cells. ${ }^{8}$ Benzenesulfonamide derivative 2 as a histone deacetylase inhibitor has been directed to treat peripheral T-cell lymphoma. ${ }^{9}$ In addition, 

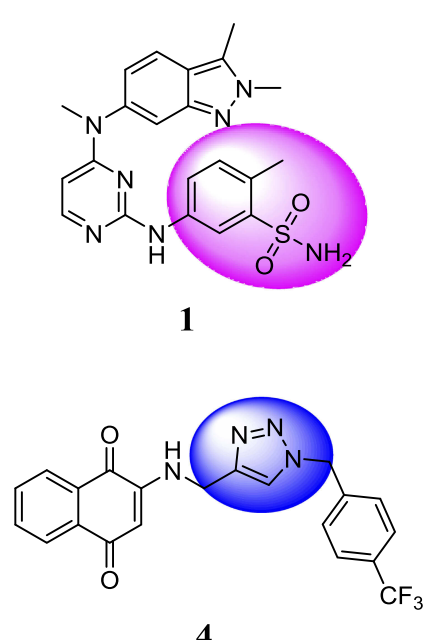

4
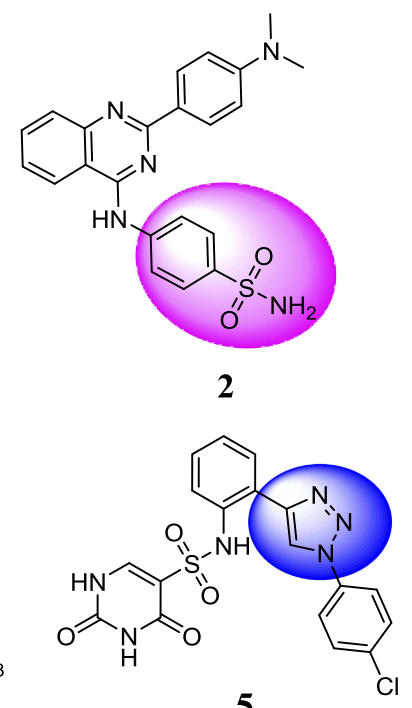

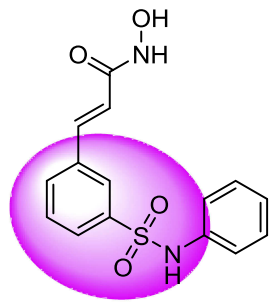

3

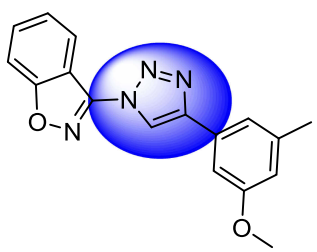

6

Figure I Anticancer benzenesulfonamide derivatives and I,2,3-triazole derivatives.

1,2,3-triazole-based heterocycles have been reported to possess the anticancer activity. ${ }^{10,11} 1,2,3$-Triazole 4 could arrest cell cycle at the G0/G1 phase in MCF-7 cells. ${ }^{12} 1,2,3-$ Triazole 5 arrested the cell cycle in the G1/S phase and induced apoptosis against A549 cells. ${ }^{13}$ 1,2,3-Triazole 6 exhibited the antiproliferative activity against acute myeloid leukemia cells by inhibiting histone deacetylases and tubulin acetylation. ${ }^{14}$ Based on these interesting findings, we hypothesised that the benzenesulfonamide-1,2,3-triazole hybrid may display the antiproliferative activity.

In continuation of our effort to obtain the bioactive benzenesulfonamide derivative with potent antitumor abilities, we reported a novel benzenesulfonamide analogue containing the 1,2,3-triazole moiety, and furthermore examined its cytotoxic effect against ovarian cancer. We also revealed that this benzenesulfonamide-1,2,3-triazole hybrid as an antitumor agent could suppress OVCAR-8 cells proliferation, migration and invasion via $\mathrm{Wnt} / \beta$-cate$\operatorname{nin} /$ GSK3 $\beta$ pathway.

\section{Materials and Methods}

\section{Synthesis of the Benzenesulfonamide} Derivative

Reagents and solvents were purchased from commercial sources. 4-Fluorobenzenesulfonyl chloride $(2 \mathrm{mmol})$ was reacted with prop-2-yn-1-amine $(3 \mathrm{mmol})$ in the presence of sodium hydroxide $(2.5 \mathrm{mmol})$ and dichloromethane $(10 \mathrm{~mL})$ to obtain the intermediate $\mathbf{7 b}$ without the further purification. ${ }^{15}$ Alkyne intermediate $7 \mathbf{b}(1 \mathrm{mmol})$, azide derivative $(1 \mathrm{mmol})$,
$\mathrm{CuSO}_{4} .5 \mathrm{H}_{2} \mathrm{O}(0.2 \mathrm{mmol})$ and sodium ascorbate $(0.1 \mathrm{mmol})$ were dissolved in acetone $/ \mathrm{H}_{2} \mathrm{O}(4 \mathrm{~mL} / 4 \mathrm{~mL})$ and stirred for 10 $\mathrm{hrs}$ at room temperature. Upon completion of the reactions, the precipitated product $\mathbf{7 c}$ was purified with column chromatography on silica gel (hexane/EtOAc $=9 / 1$ ). The chemical route and NMR data were shown in the Supporting information.

\section{Cell Culture}

Cancer cell lines (MCF7, MGC803, EC109, HepG-2, PC-3, A549, OC-314, KYSE-450 and SK-N-SH) were purchased from GeneChem (Shanghai, China), cancer cell lines (OVCAR-8, SKOV3 and Caov-3) were purchased from Type Culture Collection of the Chinese Academy of Sciences (Shanghai, China). All cells were cultured in RPMI 1640 (Hyclone, Logan, UT, USA), supplemented with 10\% foetal bovine serum (Hyclone, Logan, UT, USA) in a humidified $\mathrm{CO}_{2}(5 \%)$ incubator at $37^{\circ} \mathrm{C}$.

\section{Cell Viability Assay}

$1.0 \times 10^{5}$ cells per well were seeded in the 96-well plates. Following treatment with the compound, the cell viability was detected using the cell proliferation assay kit (Promega Corporation, Madison, WI) according to the manufacturer's protocol. The absorbance at $570 \mathrm{~nm}$ was examined by a microplate reader to analysize the $\mathrm{IC}_{50}$ values.

\section{Migration Assay}

OVCAR-8 cell line was seeded and grown in a migration plate (Corning, USA). 20\% FBS media or a vehicle was 
added in the upper bottom for 24 hrs. Fresh medium containing the compound was added to the plates. Images were taken using an inverted microscope (Nikon, Japan).

\section{Invasion Assay}

OVCAR cells were seeded in a transwell plate with the invasion membrane (LKT labs, USA). $20 \%$ FBS media or a vehicle was added in the upper bottom for $24 \mathrm{hrs}$. Fresh medium containing the compound was added for $48 \mathrm{hrs}$. Images were taken using an inverted microscope (Nikon, Japan).

\section{Western Blotting Analysis}

OVCAR cells were treated with the compound for 48 hrs. Proteins in the cell lysates were resolved by sodium dodecyl sulfate-polyacrylamide gel electrophoresis, and then transferred to polyvinylidene fluoride membrane. Then, the membranes were incubated with the primary antibodies overnight at $4^{\circ} \mathrm{C}$. The protein signals were visualized using the chemiluminescent substrate (KPL, Guildford, UK).

\section{Xenograft Study}

Animals were treated according to protocols established by the ethics committee of Zhengzhou University and the in vivo experiments were carried out in accordance with the approved guidelines and approved by the ethics committee of Zhengzhou University. Nude mice were maintained under specific pathogen-free conditions according to the Zhengzhou university committee protocol. OVCAR cells were subcutaneously injected into the right flanks of nude mice. Then, the mice were randomly assigned to the control group and the treatment group. The control group received the vehicle $(0.9 \% \mathrm{NaCl})$ alone, and the treatment group received the compound for 21 days. The body weight and tumor size of each mouse was measured every other day. All data were analysized by GraphPad software.

\section{Results and Discussion}

Globally, ovarian cancer is the seventh most common cancer in women and the eighth most common cause of cancer death, with five-year survival rates below
$45 \% .{ }^{16}$ It is necessary to develop the potent anticancer against ovarian cancer. In addition, benzenesulfonamide and 1,2,3-triazole have been reported to possess the antitumor activity. ${ }^{5,17}$ In this investigation, we synthesized a novel benzenesulfonamide-1,2,3-triazole hybrid and explored its anticancer mechanisms against ovarian cancer.

\section{Chemical Synthesis of the Benzenesulfonamide Hybrid 7c}

The novel benzenesulfonamide-1,2,3-triazole hybrid 7c was synthesized in Scheme 1. 4-Fluorobenzenesulfonyl chloride 7a was reacted with prop-2-yn-1-amine in the presence of sodium hydroxide to obtain $\mathbf{7 b}$ without the purification. $^{18,19}$ Compound $7 \mathbf{c}$ was readily synthesized from the crude product $\mathbf{7 b}$ and the 1-(azidomethyl)-3-phenoxybenzene via click reaction in the presence of copper (II) sulfate pentahydrate. The NMR data of this benzenesulfonamide-1,2,3-triazole hybrid 7c were shown in the Supporting information.

\section{Benzenesulfonamide Hybrid 7c Was a Potential Antiproliferative Agent Against Various Cancer Cell Lines}

In order to investigate the antiproliferation ability of compound 7c, MCF7 cells (breast cancer cells), MGC803 (gastric cancer cells), EC109 (esophagus cancer cells), HepG-2 (liver cancer cells), PC-3 (prostate cancer cells), A549 (lung cancer cells), OC-314 (ovarian cancer cells), KYSE-450 (esophagus cancer cells), and SK-N-SH (neuroblastic cancer cells) were treated with compound $7 \mathrm{c}$ at different concentrations (control, $2 \mu \mathrm{M}$, $4 \mu \mathrm{M}$, and $8 \mu \mathrm{M}$ ). From the results of Figure 2, compound $7 \mathbf{c}$ displayed the potential antiproliferative activity against all these cancer cell lines. Among them, compound 7c showed the most potent antiproliferation efficiency around $70 \%$ and $80 \%$ for $48 \mathrm{hrs}$ and $72 \mathrm{hrs}$ at $4 \mu \mathrm{M}$ concentration against ovarian cancer OC-314 cells.

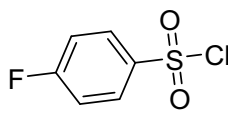

$7 \mathbf{a}$

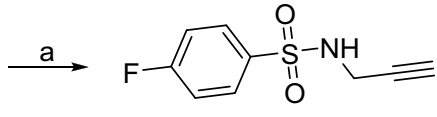

$7 b$

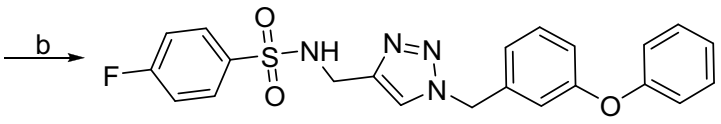

$7 \mathrm{c}$

Scheme I Reagents and conditions: (a) sodium hydroxide, prop-2-yn-I-amine, dichloromethane, rt.; (b) I-(azidomethyl)-3-phenoxybenzene, sodium ascorbate, CuSO ${ }_{4} \cdot 5 \mathrm{H}_{2} \mathrm{O}$, acetone $/ \mathrm{H}_{2} \mathrm{O}=\mathrm{I}: \mathrm{l}$. 

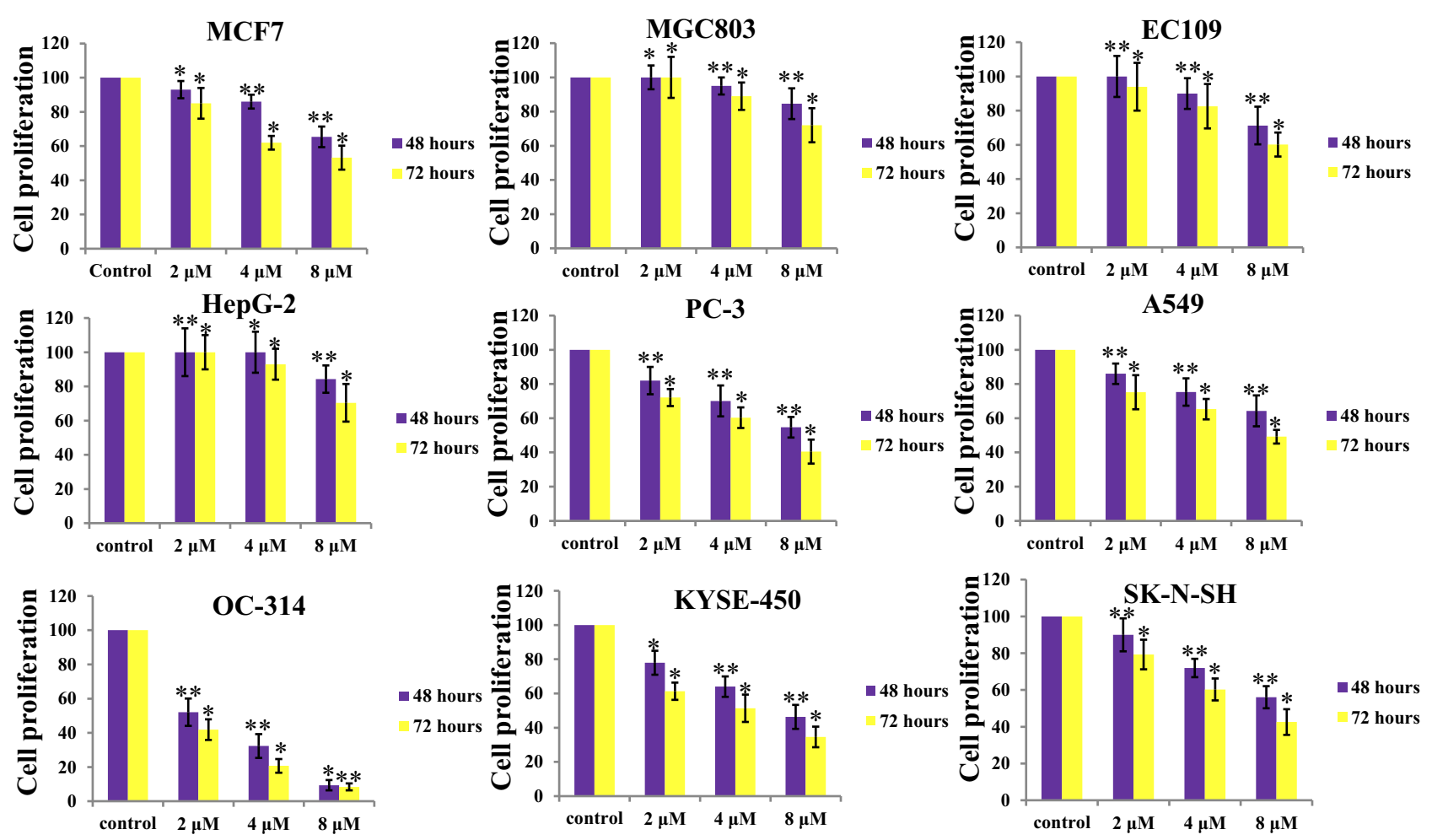

Figure 2 Antiproliferative ability of compound $7 c$ at different concentrations (control, $2 \mu \mathrm{M}, 4 \mu \mathrm{M}$, and $8 \mu \mathrm{M}$ ) for 48 hrs and 72 hrs against various cancer cell lines. The data were presented as the mean \pm SEM. $* \mathrm{P}<0.05, * * \mathrm{P}<0.01$.

\section{Benzenesulfonamide Hybrid 7c Potently Inhibited Cell Proliferation Against Ovarian Cancer}

Based on the preliminary experimental results, concentrations of $0.5 \mu \mathrm{M}, 1 \mu \mathrm{M}, 2 \mu \mathrm{M}$, and $4 \mu \mathrm{M}$ were chosen to test the proliferation effects of compound $7 \mathbf{c}$ on the cell viability of ovarian cancer cells (OC-314, OVCAR-8, SKOV3, and Caov-3). We added the 5-Fluorouracil as a positive control to do the cytotoxicity assays in cancer cell lines (OC-314, OVCAR-8, SKOV3, and Caov-3). The $\mathrm{IC}_{50}$ values of 5-Fluorouracil against OC-314, OVCAR-8, SKOV3, and Caov-3 cells were $3.12 \mu \mathrm{M}, 2.24 \mu \mathrm{M}$, $22.5 \mu \mathrm{M}$ and $10.7 \mu \mathrm{M}$, respectively. As shown in Figure 3, OVCAR-8 cells displayed a marked loss in cell viability following the treatment at $2 \mu \mathrm{M}$ and $4 \mu \mathrm{M}$ for $48 \mathrm{hrs}$. From the results of Figure 3, compound $7 \mathbf{c}$ inhibited cell proliferation with $\mathrm{IC}_{50}$ values of $1.82 \mu \mathrm{M}, 0.54 \mu \mathrm{M}, 3.91 \mu \mathrm{M}$, and $2.13 \mu \mathrm{M}$ against OC-314, OVCAR-8, SKOV3, and Caov-3 cell lines. These findings supported that the benzenesulfonamide hybrid $\mathbf{7 c}$ potently inhibited cell proliferation against ovarian cancer in a concentration-dependent manner.

\section{Benzenesulfonamide Hybrid 7c Inhibited Migration Against Ovarian Cancer OVCAR-8 Cells}

To investigate the effects of benzenesulfonamide hybrid $\mathbf{7 c}$ in endothelial cell migration against ovarian cancer OVCAR- 8 cells, the migration assay was explored according to the previous reference. ${ }^{20}$ As shown in Figure 4A and $\mathrm{C}$, the migration rates with the treatment of $7 \mathbf{c}$ for $48 \mathrm{hrs}$ at $0.25 \mu \mathrm{M}, 0.5 \mu \mathrm{M}$ and $1 \mu \mathrm{M}$ were $62.4 \%, 37.5 \%$ and $7.3 \%$, respectively. From the migration results of Figure $4 \mathrm{~B}$ and D, the migration rates with the treatment of $7 \mathbf{c}$ at $0.25 \mu \mathrm{M}$ for $24 \mathrm{hrs}, 48 \mathrm{hrs}$ and $72 \mathrm{hrs}$ were $73.3 \%, 61.4 \%$, and $20.8 \%$, respectively. All these illustrated that benzenesulfonamide1,2,3-triazole hybrid 7c could inhibit OVCAR-8 cells migration in a concentration-dependent manner.

\section{Benzenesulfonamide Hybrid 7c Could Suppress OVCAR-8 Cells Invasion}

In addition, the invasion ability of benzenesulfonamide1,2,3-triazole hybrid 7c against OVCAR-8 cells was also evaluated by matrigel-coated transwell. Based on the invasion results of Figure $5 \mathrm{~A}$ and $\mathrm{C}$, the invasion rates with the 

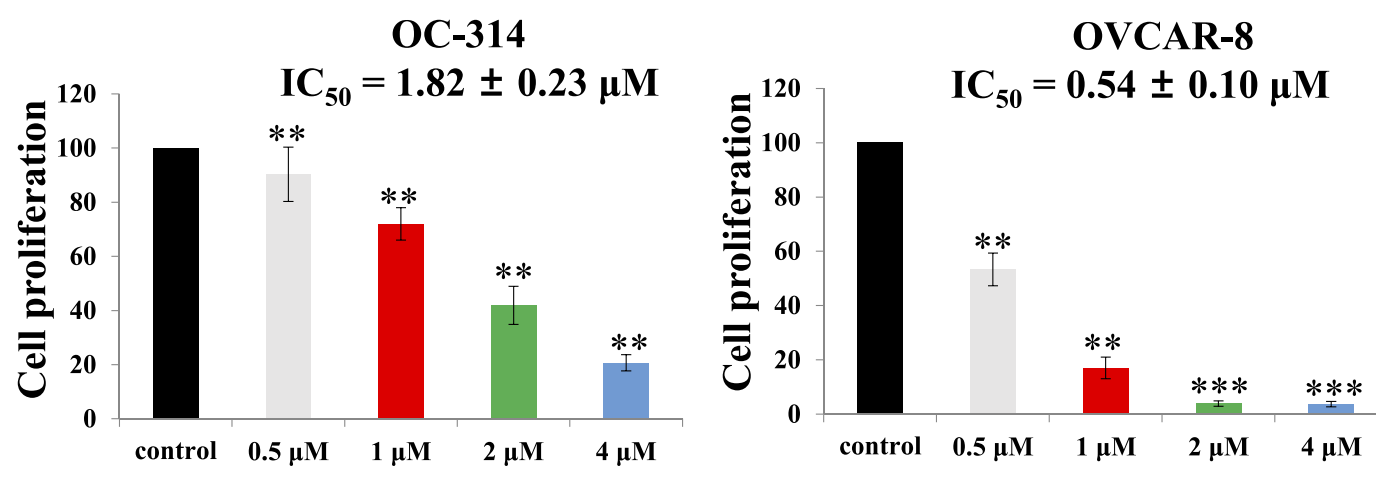

SKOV3
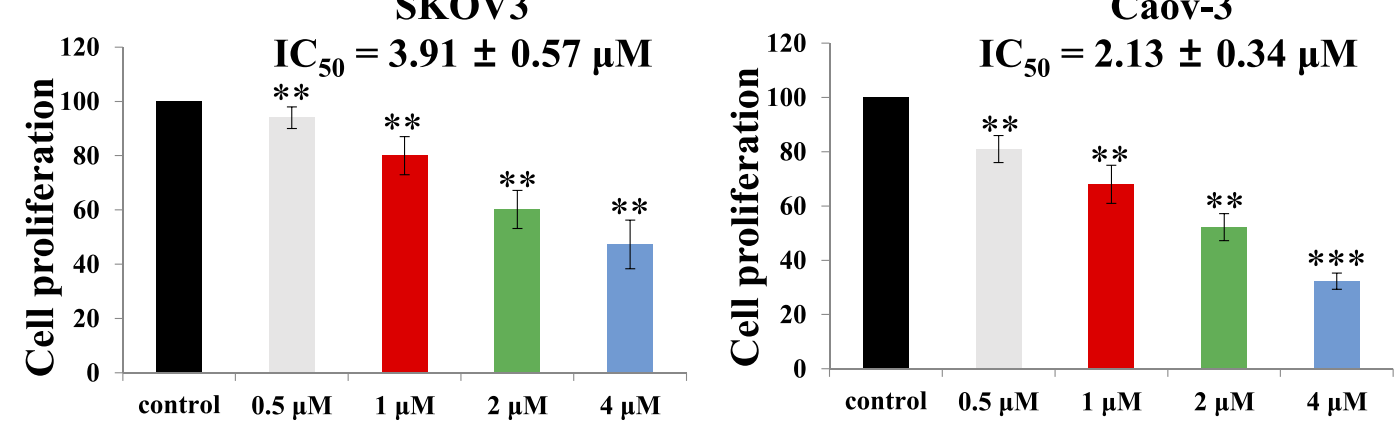

Figure 3 Benzenesulfonamide 7c potently inhibited cell proliferation against ovarian cancer cell lines (OC-3/4, OVCAR-8, SKOV3, and Caov-3) in a concentrationdependent manner. The data were presented as the mean \pm SEM. $* * \mathrm{P}<0.01$, *** $\mathrm{P}<0.001$.

A

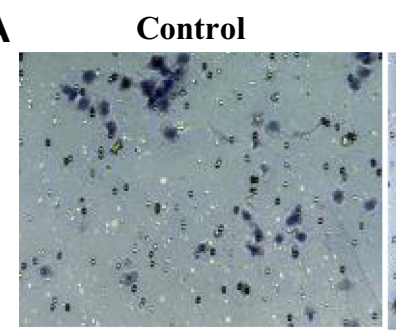

B
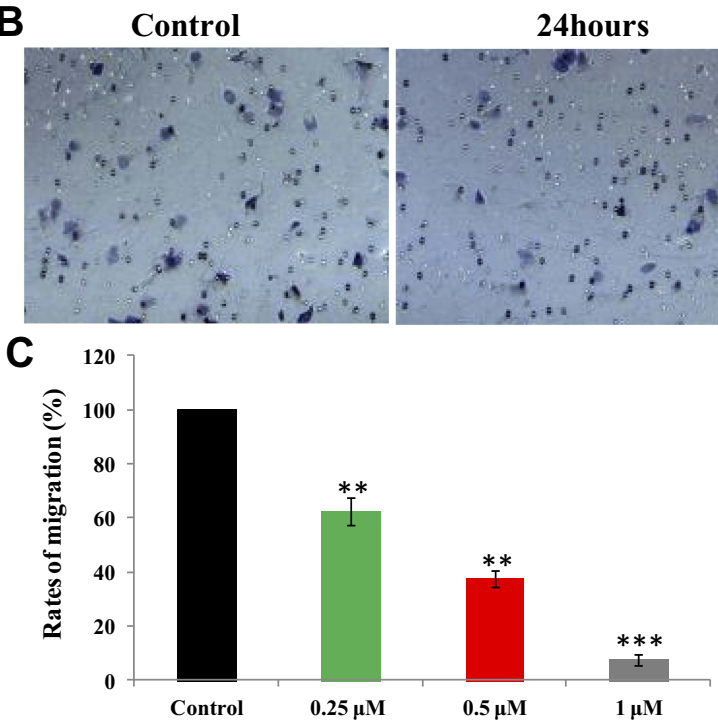

$0.25 \mu \mathrm{M}$

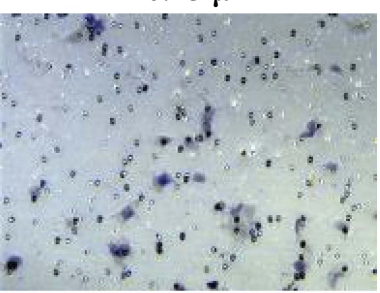

24hours

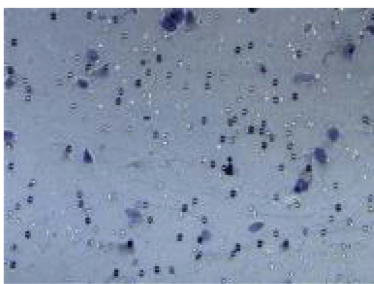

D

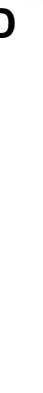

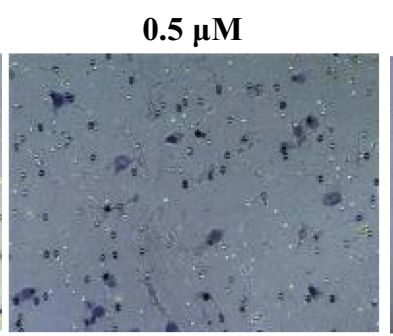

48 hours
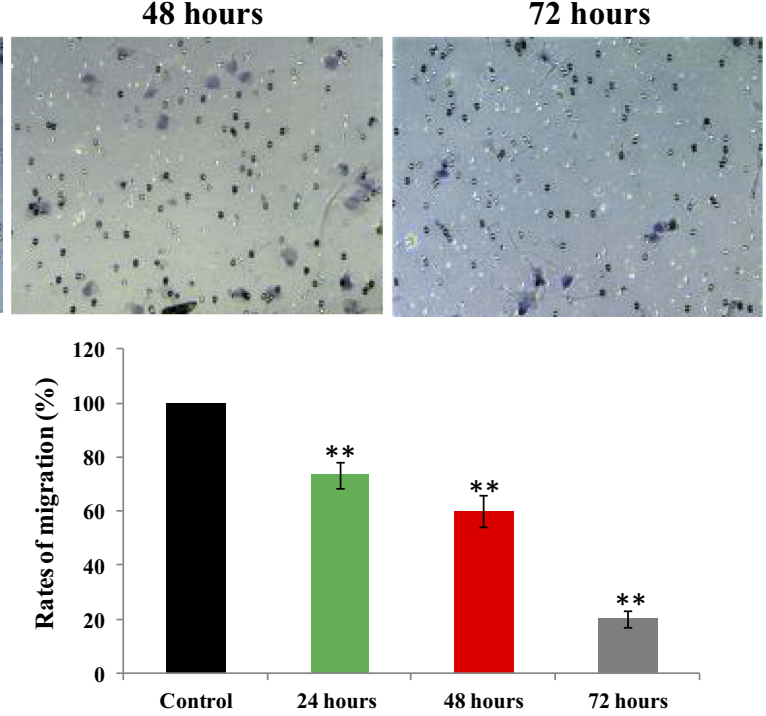

Figure 4 (A and C): OVCAR-8 cells were treated with 7 c for 48 hrs at $0.25 \mu \mathrm{M}, 0.5 \mu \mathrm{M}$ and I $\mu \mathrm{M}$ to evaluate the migration rates. (B and $\mathbf{D})$ : OVCAR-8 cells were treated with $7 \mathrm{c}$ at $0.25 \mu \mathrm{M}$ for $24 \mathrm{hrs}, 48 \mathrm{hrs}$ and $72 \mathrm{hrs}$ to evaluate the migration rates. $* * \mathrm{P}<0.0 \mathrm{l}$ and $* * * \mathrm{P}<0.00 \mathrm{I}$ were considered statistically significant compared with the control. 

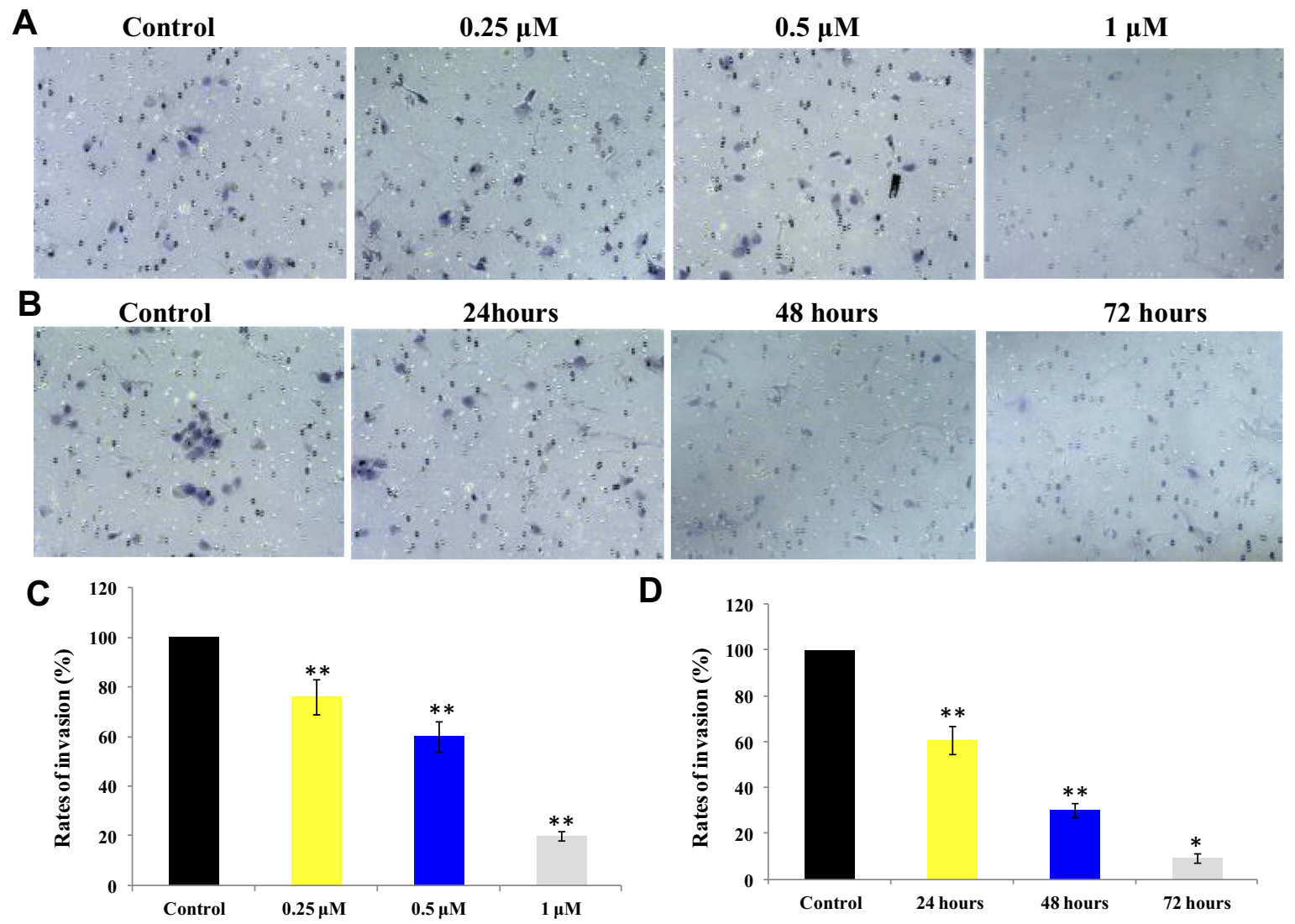

D

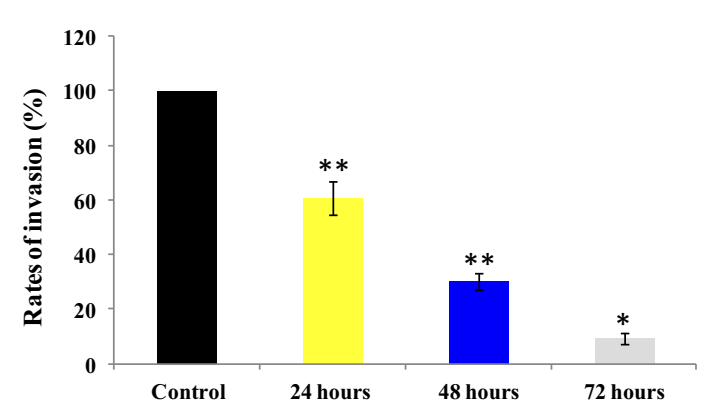

Figure 5 (A and C): OVCAR-8 cells were treated with $7 \mathrm{c}$ for 48 hrs at $0.25 \mu \mathrm{M}, 0.5 \mu \mathrm{M}$ and I $\mu \mathrm{M}$ to evaluate the invasion effects. (B and D): OVCAR-8 cells were treated with 7c at $0.5 \mu \mathrm{M}$ for $24 \mathrm{hrs}, 48 \mathrm{hrs}$ and $72 \mathrm{hrs}$ to evaluate the invasion effects. $* * \mathrm{P}<0.01$ and $* \mathrm{P}<0.05$ were considered statistically significant compared with the control.

treatment of $7 \mathrm{c}$ for $48 \mathrm{hrs}$ at $0.25 \mu \mathrm{M}, 0.5 \mu \mathrm{M}$ and $1 \mu \mathrm{M}$ were $76.1 \%, 60.2 \%$ and $20.3 \%$, respectively. When OVCAR-8 cells were treated with $7 \mathrm{c}$ at $0.5 \mu \mathrm{M}$, the invasion rates for $24 \mathrm{hrs}, 48 \mathrm{hrs}$ and $72 \mathrm{hrs}$ were $60.6 \%$, $30.4 \%$, and $9.1 \%$, respectively. The matrigel offered a simulant biologicalstroma, and ovarian cancer OVCAR-8 cells were blocked to invade by the benzenesulfonamide hybrid 7c in a concentration-dependent and time-dependent manner.

\section{Benzenesulfonamide Hybrid 7c Affected the Epithelial-Mesenchymal Transition Related Markers}

The phenomenon that epithelial cells acquire mesenchymal traits, termed as epithelial-mesenchymal transition (EMT), has been observed in physiological and pathological processes, including cancer progression. ${ }^{21}$ Loss of E-cadherin and increase of $\mathrm{N}$-cadherin expression levels were considered key events in an EMT process where the cell polarityrelated cytoskeleton, cell-cell contacting modulators and extracellular matrix were involved. ${ }^{22}$ Based on the migration and invasion effects of benzenesulfonamide-1,2,3-triazole hybrid 7c against OVCAR-8 cells, the expression levels of EMT related markers (E-cadherin, N-cadherin and Snail-1) were evaluated by Western blot methods. As shown in Figure 6, benzenesulfonamide-1,2,3-triazole hybrid 7c could decrease the expression levels of $\mathrm{N}$-cadherin and Snail-1, and increase the expression level of E-cadherin in a concentration-dependent manner.

\section{Benzenesulfonamide Hybrid 7c Affected the Wnt/ $\beta$-Catenin/GSK3 $\beta$ Pathway Against Ovarian Cancer OVCAR-8 Cells}

$\mathrm{Wnt} / \beta$-catenin is a conserved cell-signaling system that is involved numerous biological processes such as organogenesis in multicellular organisms cancer pathogenesis and the epithelial-mesenchymal transition (EMT) process. $^{23}$ Some 1,2,3-triazoles recently described as inhibitors of the wnt/ $\beta$-catenin signaling pathway. ${ }^{24}$ In addition, celecoxib as a sulfonamide selective COX-2 inhibitor inhibited 

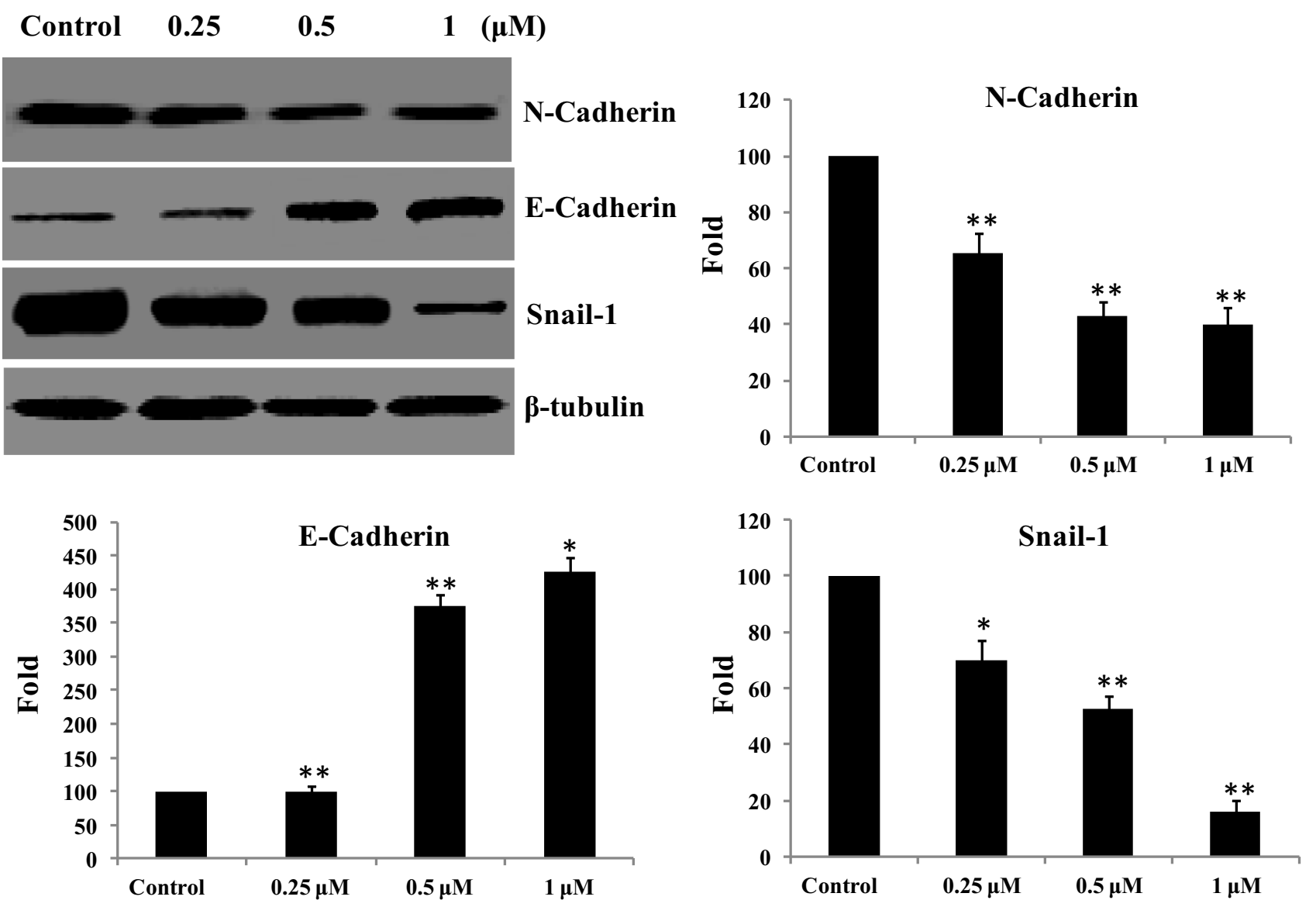

Figure 6 OVCAR-8 cells were treated with $7 \mathrm{c}$ for 48 hrs at $0.25 \mu \mathrm{M}, 0.5 \mu \mathrm{M}$ and I $\mu \mathrm{M}$ to test the expression levels of EMT related markers (E-cadherin, N-cadherin, and Snail-1). $* * \mathrm{P}<0.01$ and $* \mathrm{P}<0.05$ were considered statistically significant compared with the control.

human colon cancer cell proliferation by suppressing the Wnt/ $\beta$-catenin signaling pathway. ${ }^{25}$ Because of the same 1,2,3-triazole scaffold in the hybrid 7c, we also explored its effects on the wnt/ $\beta$-catenin signaling pathway. Glycogen synthase kinase-3 $\beta$ (GSK3 $\beta$ ) as a serine/threonine protein kinase has been implicated in a wide range of diseases including cancer. ${ }^{26}$ The inhibition of GSK-3 $\beta$ could lead to $\beta$-catenin activation and tumor cell proliferation. ${ }^{27}$ There is increasing evidence to show that GSK3 $\beta$ was aberrantly activated in various cancer types and related to tumor invasion. ${ }^{28}$ To further investigate whether compound $7 \mathbf{c}$ inhibited OVCAR-8 cells migration and invasion via a wnt/ $\beta$-catenin signaling pathway, seven wnt/ $\beta$-catenin pathway-related proteins of Wnt $3 \mathrm{a}, \beta$-catenin, GSK3 $\beta$, C-Myc, Cyclin-D, Axin2 and TCF4 were tested in OVCAR-8 cells and examined by Western blot analysis. Western blot analysis showed that the expression level of GSK3 $\beta$ was significantly enhanced after treatment of OVCAR-8 cells with compound 7c compared with the control group (Figure 7). The results exhibited that proteins Wnt 3a, $\beta$-catenin, C-Myc, Cyclin-D, Axin2, and TCF4 were significantly downregulated after $48 \mathrm{hrs}$ treatment.

\section{In vivo Antitumor Study of \\ Benzenesulfonamide Hybrid 7c}

To elucidate the antitumor effects of benzenesulfonamide1,2,3-triazole hybrid 7c in vivo, OVCAR-8 xenograft models were used. Tumor-bearing mice were then randomly assigned to two groups (control and $100 \mathrm{mg} / \mathrm{kg}$ 7c) with 5 mice per group. The treatment group received intragastric administration of 7c per day for a period of 21 days. The results showed that benzenesulfonamide 7c suppressed OVCAR-8 subcutaneous tumor growth (Figure 8). The average tumor weights of control and benzenesulfonamide-1,2,3-triazole hybrid 7c groups were $1.23 \pm 0.30 \mathrm{~g}$ and $0.47 \pm 0.20 \mathrm{~g}$ (inhibitory rate: $61.79 \%$ ), respectively. The relative tumor volume in the benzenesulfonamide 7c group $(100 \mathrm{mg} / \mathrm{kg})$ was reduced. Benzenesulfonamide 7c treatment did not significantly decrease the mouse body 

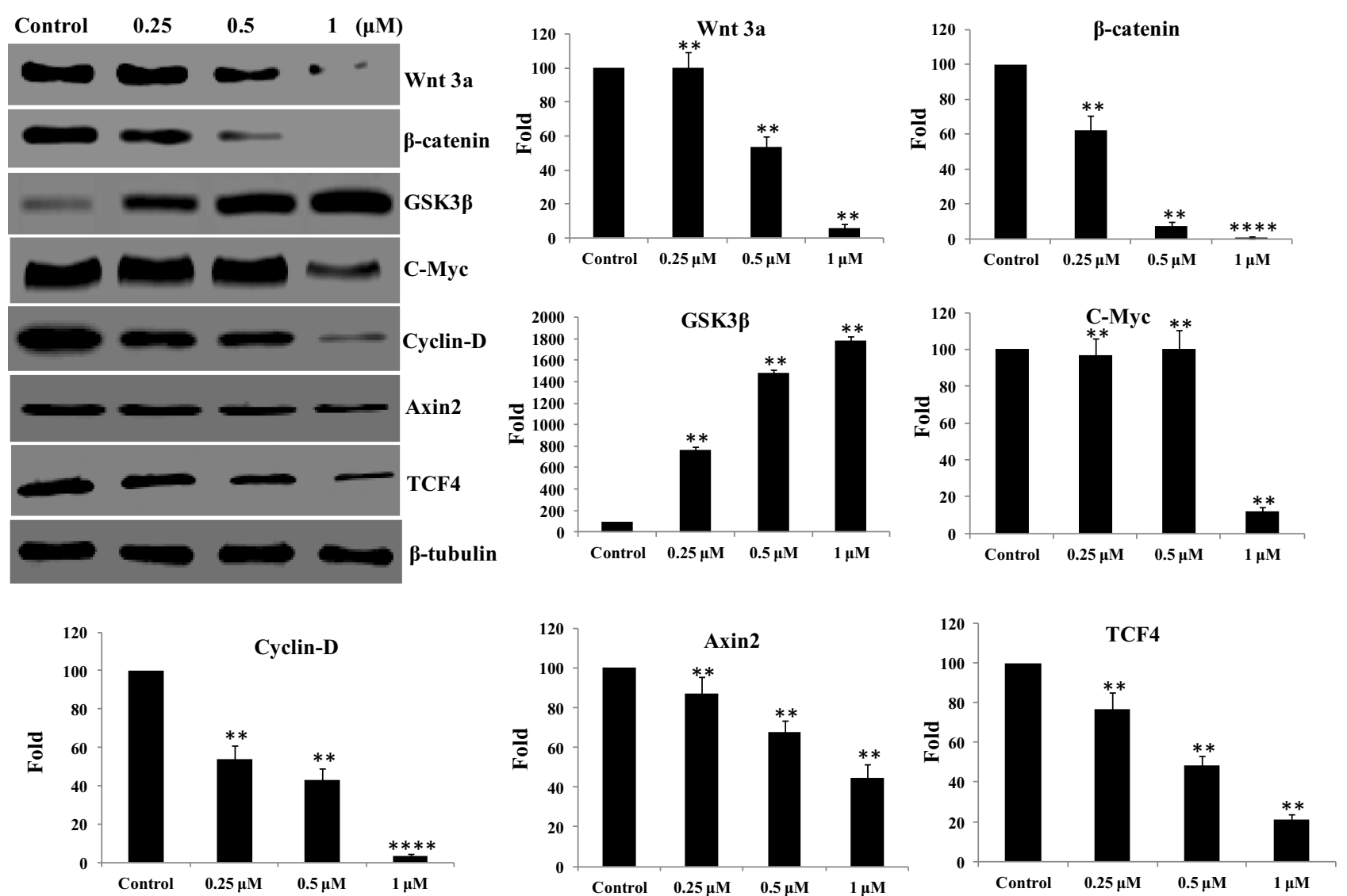

Figure 7 OVCAR-8 cells were treated with $7 \mathrm{c}$ for $48 \mathrm{hrs}$ at $0.25 \mu \mathrm{M}, 0.5 \mu \mathrm{M}$ and $\mathrm{I} \mu \mathrm{M}$ to explore the expression levels (Wnt 3a, $\beta$-catenin, GSK3 3 , C-Myc, Cyclin-D, Axin2 and TCF4). **P $<0.01$ and $* * * * 0.0001$ were considered statistically significant compared with the control.

A

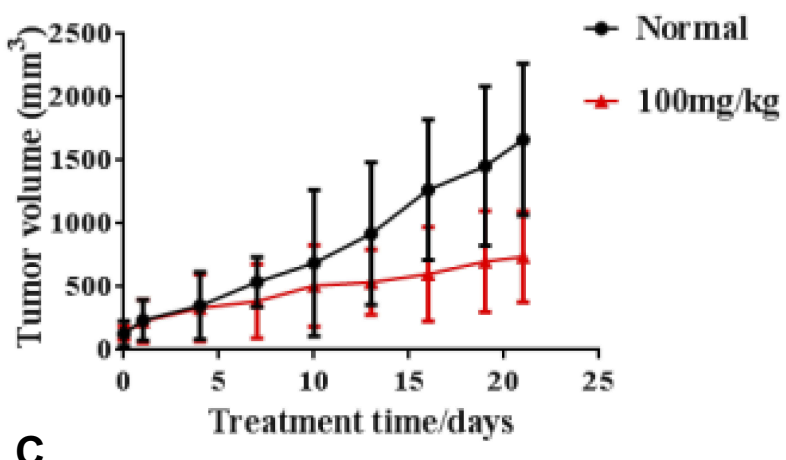

C

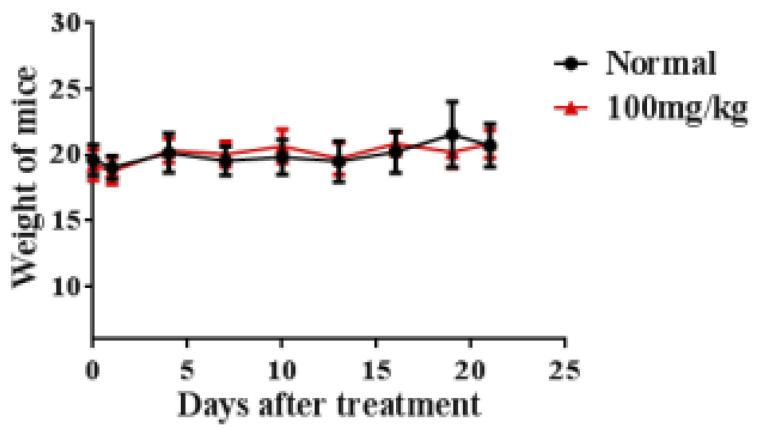

B

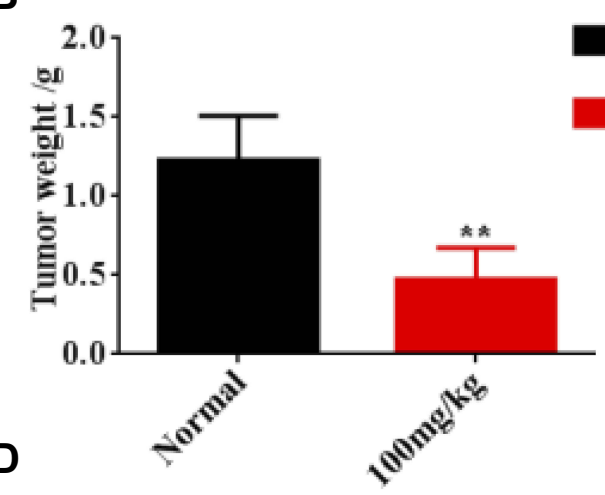

Normal

$100 \mathrm{mg} / \mathrm{kg}$

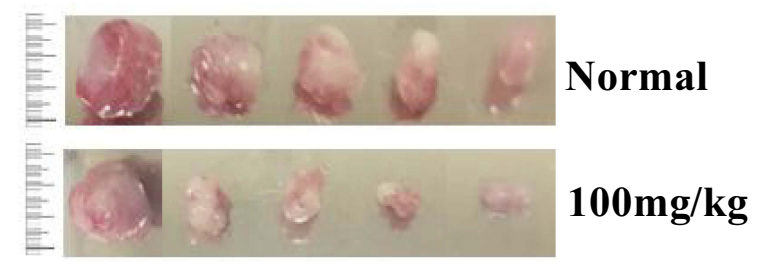

Figure 8 In vivo antitumor effects of compound 7c. (A): Tumor volume. (B): Tumor weight. (C): Body weight. (D): Representative tumor size after treatment with compound 7c. ${ }^{* * P}<0.01$ were considered statistically significant compared with the controls. 
weight compared with that of the control. As shown in Figure 8, compound 7c inhibited tumor growth remarkably, suggesting its antitumor efficacy.

\section{Conclusion}

In this work, we synthesized a novel benzenesulfonamide1,2,3-triazole hybrid, and furthermore examined its cytotoxic effect against nine cancer cell lines (MCF7, MGC803, EC109, HepG-2, PC-3, A549, OC-314, KYSE-450, and SK-N-SH). Among them, compound 7c showed the most potent antiproliferation effects against ovarian cancer OC-314 cells with percentages of $32.3 \%$ and $20.7 \%$ for $48 \mathrm{hrs}$ and $72 \mathrm{hrs}$ at $4 \mu \mathrm{M}$ concentration. In addition, compound $7 \mathrm{c}$ inhibited cell proliferation with $\mathrm{IC}_{50}$ values of $1.82 \mu \mathrm{M}, 0.54 \mu \mathrm{M}, 3.91 \mu \mathrm{M}$, and $2.13 \mu \mathrm{M}$ against OC-314, OVCAR-8, SKOV3, and Caov3 cell lines, investigating that compound $7 \mathrm{c}$ displayed the potent antiproliferation effects against ovarian cancer.

Furthermore, benzenesulfonamide-1,2,3-triazole hybrid 7c potently inhibited migration and invasion against ovarian cancer OVCAR-8 cells in a concentration-dependent and time-dependent manner. It could decrease the expression levels of Wnt 3a, $\beta$-catenin, C-Myc, Cyclin-D, Axin2, TCF4, N-cadherin and Snail-1, and increase the expression levels of E-cadherin and GSK3 $\beta$. All these results revealed that compound 7c affected the Wnt/ $\beta$-catenin/GSK3 $\beta$ pathway against ovarian cancer OVCAR-8 cells. Importantly, compound 7c inhibited tumor growth remarkably, while the body weight was almost unchanged, suggesting the antitumor efficacy and low global toxicity. Collectively, we identify that compound $7 \mathbf{c}$ could be a lead compound for further antitumor drug discovery to treat ovarian cancer.

\section{Acknowledgment}

The authors thank the support from First Affiliated Hospital of Zhengzhou University.

\section{Disclosure}

The authors report no conflicts of interest in this work.

\section{References}

1. Xiong D-D, Qin Y, Xu W-Q, et al. A network pharmacology-based analysis of multi-target, multi-pathway, multi-compound treatment for ovarian serous cystadenocarcinoma. Clin Drug Investig. 2018;38:909925. doi:10.1007/s40261-018-0683-8

2. Kwon JS, Tinker AV, Hanley GE, et al. BRCA mutation testing for first-degree relatives of women with high-grade serous ovarian cancer. Gynecol Oncol. 2019;152:459-464. doi:10.1016/j.ygyno.2018. 10.014
3. Murakami R, Matsumura N, Michimae H, et al. The mesenchymal transition subtype more responsive to dose dense taxane chemotherapy combined with carboplatin than to conventional taxane and carboplatin chemotherapy in high grade serous ovarian carcinoma: A survey of Japanese Gynecologic Oncology Group study (JGOG3016A1). Gynecol Oncol. 2019;153:312-319. doi:10.1016/j.ygyno.2019.02.010

4. Lisio M-A, Fu L, Goyeneche A, Gao Z-H, Telleria C. High-grade serous ovarian cancer: basic sciences, clinical and therapeutic standpoints. Int J Mol Sci. 2019;20:952. doi:10.3390/ijms2004 0952

5. Wu T-Y, Cho T-Y, Lu C-K, Liou J-P, Chen M-C. Identification of 7(4'-Cyanophenyl)indoline-1-benzenesulfonamide as a mitotic inhibitor to induce apoptotic cell death and inhibit autophagy in human colorectal cancer cells. Sci Rep. 2017;7:12406. doi:10.1038/s41598017-12795-5

6. Ghorab MM, Alsaid MS, Soliman AM, Ragab FA. VEGFR-2 inhibitors and apoptosis inducers: synthesis and molecular design of new benzo[g] quinazolin bearing benzenesulfonamide moiety. J Enzyme Inhib Med Chem. 2017;32:893-907. doi:10.1080/14756366.2017.1334650

7. Yang J, Yang S, Zhou S, et al. Synthesis, anti-cancer evaluation of benzenesulfonamide derivatives as potent tubulin-targeting agents. Eur J Med Chem. 2016;122:488-496. doi:10.1016/j.ejmech.2016. 07.002

8. Al-Obeed O, Vaali-Mohammed M-A, Eldehna WM, et al. Novel quinazoline-based sulfonamide derivative (3D) induces apoptosis in colorectal cancer by inhibiting JAK2-STAT3 pathway. Onco Targets Ther. 2018;11:3313-3322. doi:10.2147/OTT.S148108

9. Żołnowska B, Sławiński J, Brzozowski Z, et al. Synthesis, molecular structure, anticancer activity, and QSAR Study of N-(aryl/heteroaryl)-4-(1H-pyrrol-1-yl)benzenesulfonamide derivatives. Int $\mathrm{J} \mathrm{Mol}$ Sci. 2018;19:1482. doi:10.3390/ijms19051482

10. Qiu Q, Zhu J, Chen Q, et al. Discovery of aromatic amides with triazole-core as potent reversal agents against P-glycoproteinmediated multidrug resistance. Bioorg Chem. 2019;90:103083. doi:10.1016/j.bioorg.2019.103083

11. Gregorić T, Sedić M, Grbčić P, et al. Novel pyrimidine-2,4-dione1,2,3-triazole and furo[2,3-d]pyrimidine-2-one-1,2,3-triazole hybrids as potential anti-cancer agents: synthesis, computational and X-ray analysis and biological evaluation. Eur J Med Chem. 2017;125:12471267. doi:10.1016/j.ejmech.2016.11.028

12. Gholampour M, Ranjbar S, Edraki N, Mohabbati M, Firuzi O, Khoshneviszadeh M. Click chemistry-assisted synthesis of novel aminonaphthoquinone-1,2,3-triazole hybrids and investigation of their cytotoxicity and cancer cell cycle alterations. Bioorg Chem. 2019;88:102967. doi:10.1016/j.bioorg.2019.102967

13. Lu G-Q, Li X-Y, Mohamed OK, Wang D, Meng F-H. Design, synthesis and biological evaluation of novel uracil derivatives bearing 1,2, 3-triazole moiety as thymidylate synthase (TS) inhibitors and as potential antitumor drugs. Eur J Med Chem. 2019;171:282-296. doi:10.1016/j.ejmech.2019.03.047

14. Ashwini N, Garg M, Mohan CD, et al. Synthesis of 1,2-benzisoxazole tethered 1,2,3-triazoles that exhibit anticancer activity in acute myeloid leukemia cell lines by inhibiting histone deacetylases, and inducing p21 and tubulin acetylation. Bioorg Med Chem. 2015;23:6157-6165. doi:10.1016/j.bmc.2015.07.069

15. Fu D-J, Liu J-F, Zhao R-H, Li J-H, Zhang S-Y, Zhang Y-B. Design and antiproliferative evaluation of novel sulfanilamide derivatives as potential tubulin polymerization inhibitors. Molecules. 2017;22:1470. doi:10.3390/molecules22091470

16. Webb PM, Jordan SJ. Epidemiology of epithelial ovarian cancer. Best Pract Res Clin Obstet Gynaecol. 2017;41:3-14. doi:10.1016/j. bpobgyn.2016.08.006

17. Prasad B, Lakshma Nayak V, Srikanth PS, et al. Synthesis and biological evaluation of 1-benzyl-N-(2-(phenylamino)pyridin-3-yl)1H-1,2,3-triazole-4-carboxamides as antimitotic agents. Bioorg Chem. 2019;83:535-548. doi:10.1016/j.bioorg.2018.11.002 
18. Bistrović A, Harej A, Grbčić P, et al. Synthesis and anti-proliferative effects of mono- and bis-purinomimetics targeting kinases. Int $\mathrm{J} \mathrm{Mol}$ Sci. 2017;18:2292. doi:10.3390/ijms18112292

19. Singh K, Sona C, Ojha V, et al. Identification of dual role of piperazine-linked phenyl cyclopropyl methanone as positive allosteric modulator of 5-HT2C and negative allosteric modulator of 5-HT2B receptors. Eur J Med Chem. 2018;164:499-516.

20. Luo K, Bao Y, Liu F, et al. Synthesis and biological evaluation of novel benzylidene-succinimide derivatives as noncytotoxic antiangiogenic inhibitors with anticolorectal cancer activity in vivo. Eur J Med Chem. 2019;179:805-827. doi:10.1016/j.ejmech.2019. 06.094

21. Ruscetti M, Quach B, Dadashian EL, Mulholland DJ, Tracking WH. And functional characterization of epithelial-mesenchymal transition and mesenchymal tumor cells during prostate cancer metastasis. Cancer Res. 2015;75:2749-2759. doi:10.1158/0008-5472.CAN-143476

22. Chen T, You Y, Jiang H, Wang ZZ. Epithelial-mesenchymal transition (EMT): a biological process in the development, stem cell differentiation, and tumorigenesis. J Cell Physiol. 2017;232:3261-3272. doi:10.1002/jcp.v232.12
23. Jacques BE, Montgomery IW, Uribe $H$, et al. The role of Wnt/ $\beta$ catenin signaling in proliferation and regeneration of the developing basilar papilla and lateral line. Dev Neurobiol. 2014;74:438-456. doi:10.1002/dneu.22134

24. Obianom ON, Ai Y, Li Y, et al. Triazole-based inhibitors of the Wnt/ $\beta$-Catenin signaling pathway improve glucose and lipid metabolisms in diet-induced obese mice. J Med Chem. 2019;62:727-741. doi:10.1021/acs.jmedchem.8b01408

25. Egashira I, Takahashi-Yanaga F, Nishida R, et al. Celecoxib and 2,5dimethylcelecoxib inhibit intestinal cancer growth by suppressing the Wnt/ $\beta$-catenin signaling pathway. Cancer Sci. 2017;108:108-115. doi:10.1111/cas.2017.108.issue-1

26. Walz A, Ugolkov A, Chandra S, et al. Molecular pathways: revisiting glycogen synthase kinase-3 $\beta$ as a target for the treatment of cancer. Clin Cancer Res. 2017;23:1891-1897. doi:10.1158/1078-0432.CCR-15-2240

27. Mancinelli R, Carpino G, Petrungaro S, et al. Multifaceted roles of GSK-3 in cancer and autophagy-related diseases. Oxid Med Cell Longev. 2017;2017:4629495. doi:10.1155/2017/4629495

28. Pardo M, Abrial E, Jope RS, Beurel E. GSK3 $\beta$ isoform-selective regulation of depression, memory and hippocampal cell proliferation. Genes Brain Behav. 2016;15:348-355. doi:10.1111/gbb.2016.15.issue-3

\section{Publish your work in this journal}

Drug Design, Development and Therapy is an international, peerreviewed open-access journal that spans the spectrum of drug design and development through to clinical applications. Clinical outcomes, patient safety, and programs for the development and effective, safe, and sustained use of medicines are a feature of the journal, which has also been accepted for indexing on PubMed Central. The manuscript management system is completely online and includes a very quick and fair peer-review system, which is all easy to use. Visit http://www. dovepress.com/testimonials.php to read real quotes from published authors. 